\title{
Perinatal Exposure
}

National Cancer Institute

\section{Source}

National Cancer Institute. Perinatal Exposure. NCI Thesaurus. Code C19942.

Exposure to potentially harmful chemical, physical, or biological agents in utero or preconception. 